\section{Are fluoride levels in drinking water associated with hypothyroidism prevalence in England? Comments on the authors' response to earlier criticism}

Academic debate is healthy and helps us to clarify the evidence base for the interested reader. However, it is unusual for a peer-reviewed paper in a reputable journal to receive quite as much criticism as that which greeted publication of the paper by Peckham et al on fluoride and hypothyroidism. ${ }^{1}$ Two highly critical commentaries were published at the time. ${ }^{2}{ }^{3} \mathrm{~A}$ subsequent review article ${ }^{4}$ in the Journal of Evidence-based Dental Practice concluded that "this study is an ecologic one that has several significant flaws, making it almost meaningless with regard to assessing any possible association between water fluoridation and hypothyroidism."

Published criticisms included lack of a coherent basis for a prior hypothesis, unbalanced citing of the literature, failure to allow for potential confounding, inadequate recognition of the limitations of ecological studies, imprecise measurement of exposure and outcomes, and over interpretation of the results to infer causation. Statistical aspects of the study were particularly heavily criticised by Warren et $a l^{4}$ for lack of transparency in reporting, the use of arbitrary categorical cut points to analyse a continuous variable, and by $\mathrm{us}^{3}$ for some apparently anomalous results in relation to deprivation.

The authors have now responded to the criticism and readers can draw their own conclusions as to the adequacy of that response.

The quote from the NRC report is a helpful clarification, but extensive discussion in that report of the weaknesses of the evidence base is still not acknowledged. The relevant studies are mainly correlation studies in rural developing world communities with limited data on intermediate end points and recognised methodological weaknesses. These studies have little, if any, relevance to exposures due to water fluoridation schemes in the UK. Also, Peckham et al accept that hypothyroidism has multiple immediate causes (auto-immune, surgical etc) but do not acknowledge that this makes any unifying hypothesis of association with fluoride exposure intrinsically implausible.
We continue to believe that confounding has been inadequately considered. Age and sex may have been partly accounted for but only at aggregate level not at individual level (the ecological fallacy). The data presented in figures $1 \mathrm{~s}$ and $2 \mathrm{~s}$ are poorly explained and are not clearly attributable to, and indeed postdate, the reference cited. The figures appear to show different distributions of iodine intake in 'fluoridated' compared to 'non-fluoridated' regions, which if anything suggests that iodine exposure may indeed be an important confounder. However, having examined the source we do not understand how the National Diet and Nutrition Survey can be analysed by 'fluoridated and nonflouridated SHA areas' or for women aged over 40 years, since it does not use such an age range and is not sufficiently precise to allow small-area aggregation (fluoridation does not occur at SHA level). Peckham et al are mistaken, we refer in our commentary to a different article by Vanderpump ${ }^{5}$ to the one cited by Grimes. Other potential confounders mentioned in the NRC report such as selenium, calcium and aluminium are not considered, let alone a myriad of unknown and unmeasured variables related to population or health service factors.

On the comparisons made, there is still no information on how the two city areas were defined or why other areas were excluded. It seems the journal peer reviewer recommended a categorical approach instead of the analysis of continuous variables. Without seeing the review in question it is hard to comment further, except to say that it would appear to us to be poor advice. No explanation is given as to why tertiles of deprivation and hypothyroidism, respectively, were combined into binary outcomes differently. The justification for the fluoride exposure category seems to be related to therapeutic efficacy which was not the subject of the study. As has been pointed out what we need to be confident about the analysis is a clear descriptive table to help us to understand the data not a few coefficients presented as outcomes.

We were fascinated to discover that the direction of association between deprivation and hypothyroidism switched direction in their model after adjustment for proportion aged over 40 years (OR changed from 0.49 to 1.7$)$. Although good to know that it was not an error, discovery of such a statistical quirk in the model (which we believe is an extreme example of Simpson's paradox ${ }^{6}$ ) raises more questions than it provides answers about the relevance and validity of the model for the hypothesis being examined.

Returning to the question of interpretation, we do not agree that an association has been demonstrated let alone a causal one. Peckham et al quote a recent Irish review $^{7}$ - this is what it has to say in conclusion about their study: "There are three reasons for assigning a low-quality rating. First, the study design assigned was incorrect. Second, the control for confounding was incomplete. Third, the authors infer a causal relationship rather than a theoretical relationship."

It is a fact that a question has been raised if not answered by this study. Rather than continue to debate with its authors we plan to repeat the analysis ourselves using more conventional statistical methods. In the meantime, it is unfortunate that this article and its claims remain in the literature despite its weaknesses. The BMJ website shows that it has achieved an Altimetric score at the time of writing of 357 with extensive activity in North America whereas the critical commentaries have scores of just 14 and 16 with no US coverage.

Water fluoridation is a well-established and highly effective public health intervention with a safety record that spans many decades. It is important that the public and policymakers receive clear and measured advice on its safety and effectiveness based on the best available science.

\section{John N Newton, ${ }^{1}$ Julia Verne, ${ }^{2}$ Mark Dancox, ${ }^{2}$ Nicholas Young ${ }^{3}$}

${ }^{1}$ Department of Chief Knowledge Officer, Public Health England, London, UK

${ }^{2}$ Department of South West Knowledge and Intelligence Team, Public Health England, Bristol, UK

${ }^{3}$ Department of Knowledge and Intelligence Team, Public Health England, Bristol, UK

Correspondence to Professor John N Newton, Department of Chief Knowledge Officer, Public Health England, PHE, Wellington House 135-155 Waterloo Road, London SE1 8UG, UK; john.newton@phe.gov.uk

Contributors All authors contributed to the drafting of this response.

Competing interests None declared.

Provenance and peer review Commissioned; internally peer reviewed.

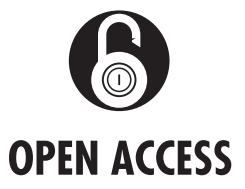

Open Access This is an Open Access article distributed in accordance with the Creative Commons Attribution Non Commercial (CC BY-NC 4.0) license, which permits others to distribute, remix, adapt, build upon this work non-commercially, and license their derivative works on different terms, provided the original work is properly cited and the use is non- 


\section{Debate}

commercial. See: http://creativecommons.org/licenses/ by-nc/4.0/

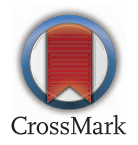

To cite Newton JN, Verne J, Dancox M, et al.

J Epidemiol Community Health 2017;71:315-316.

Received 14 November 2016

Accepted 18 November 2016

Published Online First 16 January 2017

\section{(5) Linked}

http://dx.doi.org/10.1136/jech-2016-208632

- http://dx.doi.org/10.1136/jech-2016-208773
J Epidemiol Community Health 2017;71:315-316. doi:10.1136/jech-2016-208649

\section{REFERENCES}

1 Peckham S, Lowery D, Spencer S. Are fluoride levels in drinking water associated with hypothyroidism prevalence in England? A large observational study of GP practice data and fluoride levels in drinking water. J Epidemiol Community Health 2015;69:619-24.

2 Grimes DR. Commentary on 'Are fluoride levels in drinking water associated with hypothyroidism prevalence in England? A large observational study of GP practice data and fluoride levels in drinking water'. J Epidemiol Community Health 2015: 69:616.

3 Newton JN, Young N, Verne J, et al. Water fluoridation and hypothyroidism: results of this study need much more cautious interpretation. J Epidemiol Community Health 2015;69:617-18.
4 Warren JJ, Saraiva MC. No evidence supports the claim that water fluoridation causes hypothyroidism. J Evid Based Dent Pract 2015;15:137-9.

5 Vanderpump MP, Tunbridge WM. Epidemiology and prevention of clinical and subclinical hypothyroidism. Thyroid 2002; 12:839-47.

6 Hernán MA, Clayton D, Keiding N. The Simpson's paradox unraveled. Int I Epidemiol 2011:40:780-5.

7 Sutton M, Kiersey R, Farragher L, et al. Health effects of water fluoridation. Ireland: Health Research Board, 2015. 